\title{
O papel da burocracia na Gestão da Informação
}

\author{
The role of bureaucracy in Information Management
}

\begin{abstract}
Beatriz Rosa Pinheiro dos Santos
Doutoranda pelo Programa de Pós-Graduação em Ciência da Informação da Faculdade de Filosofia e Ciências da Universidade Estadual Paulista Júlio de Mesquita Filho, campus de Marília, Brasil.

E-mail: pinheiro.santos@unesp.br

ORCID: https://orcid.org/0000-0001-8620-2612
\end{abstract}

Ieda Pelógia Martins Damian

Doutora em Administração de Organizações pela Faculdade de Economia, Administração e Contabilidade de Ribeirão Preto, FEA-RP/USP, Brasil.

Professora do curso de Biblioteconomia e Ciência da Informação da Faculdade de Filosofia, Ciências e Letras de Ribeirão Preto da Universidade de São Paulo - FFCLRP/USP e Docente do Programa de Pós-Graduação em Ciência da Informação da Faculdade de Filosofia e Ciências da Universidade Estadual Paulista "Julio de Mesquita Filho", campus de Marília, Brasil.

E-mail: iedapm@usp.br

ORCID: http://orcid.org/0000-0001-5364-3243

\section{Resumo}

Presume-se que em uma organização, um processo burocrático bem gerenciado transfigura-se essencial para que os funcionários tenham acesso a informações precisas, de qualidade e nos momentos desejados para que decisões assertivas possam ser tomadas. Além disso, as empresas necessitam compreender o papel relevante desempenhado pela gestão burocrática no provimento da informação, uma vez que tal gestão faz parte do processo de gestão da informação. Diante disso, a presente pesquisa parte do seguinte problema: no contexto organizacional, qual é o papel da burocracia nos processos de gestão da informação? O objetivo desta pesquisa é analisar as implicações positivas e negativas da burocracia na gestão da informação e demonstrar como potencializar suas implicações positivas nos ambientes organizacionais, a fim de tornar os resultados obtidos pelos processos da gestão da informação cada vez mais expressivos. Para tanto, foi desenvolvida uma pesquisa de natureza qualitativa, do tipo exploratória e de cunho teórico. Considera-se que a gestão da informação não consegue ser implantada com eficiência se na organização existir uma burocracia com características ultrapassadas e não combinadas com a sociedade da informação.

Palavras-chave: Teoria da burocracia. Gestão da informação. Sociedade da informação. Burocracia pós-moderna.

\begin{abstract}
It is assumed that in an organization, a well-managed bureaucratic process is essential for employees to have access to accurate, quality information and at desired times for assertive decisions to be made. In addition, companies need to understand the relevant role played by bureaucratic management in providing information, since such management is part of the information management process. Given this, the present research starts from the following problem: in the organizational context, what is the role of bureaucracy in the processes of information management? The objective of this research is to analyze the positive and negative implications of bureaucracy in information management and to demonstrate how to enhance its positive implications in organizational environments in order to make the results obtained by information management processes increasingly expressive. For that, a qualitative, exploratory and theoretical research was developed. It is considered that information management cannot be effectively implemented if the organization has a bureaucracy with outdated characteristics and not combined with the information society.
\end{abstract}

Keywords: Theory of bureaucracy. Information management. Information society. Postmodern bureaucracy.

InCID: R. Ci. Inf. e Doc., Ribeirão Preto, v. 11, n. 1, p. 73-92, mar./ago. 2020.

DOI: 10.11606/issn.2178-2075.v11i1p73-92 


\section{Introdução}

De maneira empírica, pode-se afirmar que a palavra burocracia não agrada muito, porque está sempre associada a normas e regulamentos que carregam consigo lentidão, vagarosidade e ineficiência nos processos e serviços desenvolvidos pelas organizações, sejam essas públicas ou privadas. Pode-se dizer até que, em um contexto organizacional, a burocracia é uma forma de estruturação que não satisfaz nem os clientes, nem os funcionários de uma empresa, embora tenha se tornado uma situação vivida e culturalmente enraizada na sociedade.

Fato é que, o cumprimento de normas, regulamentos e regras estão bem associados a formalidades, papéis, organização e a gestão destes, e concomitantemente, a requisitos teóricos que, se aplicado em demasia, pode desfavorecer o sucesso da prática. Todavia, também não se pode desconsiderar que a eficiência da prática, por exemplo, de serviços e atividades organizacionais, é dependente de processos burocráticos que vão nortear o cumprimento das atividades.

Nessa linha de raciocínio, é interessante entender que, em uma organização, um processo burocrático bem gerenciado e otimizado transfigura-se essencial para que os funcionários tenham acesso a informações precisas, de qualidade e nos momentos desejados para que possam tomar boas decisões. Simultaneamente, é importante provir do gestor a ideia de que os procedimentos burocráticos não são apenas procedimentos que devem ser cumpridos, simplesmente porque devem ser cumpridos, mas que possui um propósito muito maior de gestão e de desenvolvimento para uma empresa. Ademais, este profissional necessita compreender que a gestão burocrática é relevante no provimento da informação, e que até mesmo faz parte do processo de gestão da informação.

Aborda-se o gestor como uma entidade importante nesse contexto, porque este se encarrega de moldar a cultura organizacional e informacional de uma organização, logo, às ações dos demais funcionários são realizadas com base no que o gestor determina e acredita, afinal, de acordo com Reis et al., (2013), a burocracia é um elemento que está atrelado à cultura das organizações e que o tratamento desse elemento é capaz de delinear a cultura organizacional ao seu favor, mesmo porque, a burocracia habilita padrões de racionalidade nas organizações, de maneira indireta e natural, e os homens, obrigatoriamente, se conformam com esses padrões de racionalidade, acreditando fielmente na sua eficácia, o que demonstra o poder que uma organização burocrática possui diante dos seus funcionários, e o quanto os processos 
burocráticos não munidos de gestão podem oferecer riscos manipuladores e catastróficos aos sujeitos organizacionais.

Segundo Chiavenato (2003), os procedimentos burocráticos são meios que as pessoas utilizam para racionalizar ações e para alcançar os objetivos com eficácia. $\mathrm{O}$ autor expressa esses procedimentos como normas formais que garantem a organização e o equilíbrio gerencial de uma empresa.

Ao mesmo passo, a forma como esses procedimentos burocráticos são expostos e executados influencia diretamente na maneira com que a informação vai ser produzida, armazenada, recuperada, acessada e utilizada pelas pessoas. Nesse sentido, os processos burocráticos possuem grandes responsabilidades na maneira em que as informações serão acessadas e desenvolvidas no ambiente organizacional.

Em vistas mais abrangentes, sabe-se que o acesso à informação é um direito inalterável que o homem possui, afinal, a informação está alicerçada pelo ser humano, na sua forma de viver e de tomar decisões (ARDENGHI, 2012). Gonçalez (2017) corrobora, afirmando que em nenhum ambiente devem existir barreiras para o acesso à informação, pois isso é o que proporciona a independência e o poder da capacidade humana.

Assim, mediante essas contextualizações, a presente pesquisa parte do seguinte problema: no contexto organizacional, qual é o papel da burocracia nos processos de gestão da informação? O objetivo é analisar as implicações positivas e negativas da burocracia e demonstrar como potencializar suas implicações positivas nos ambientes organizacionais, a fim de facilitar o processo de gestão da informação.

Para tal fim, foi desenvolvida uma pesquisa de natureza qualitativa, do tipo exploratória e de cunho teórico. Também foi desenvolvida com base em material publicado, como livros, teses, dissertações e artigos científicos, pesquisados no Portal de Periódicos CAPES, BRAPCI, SCIELO, Web of Science, Library \& Information Science Abstracts (LISA), como também no acervo Pathernon da Biblioteca pertencente à Universidade Estadual Paulista (UNESP), Faculdade de Filosofia e Ciências.

O corpo teórico da pesquisa, que envolve materiais relativos à teoria da burocracia, gestão da informação, informação para tomada de decisão e acesso à informação puderam auxiliar na discussão relativa às implicações positivas e negativas da burocracia no acesso à informação nas organizações, mediante uma visão pouco abordada na área da Ciência da 
Informação, envolvendo a burocracia como um processo que pode ser aliado (ou não) da gestão da informação, enfatizando o acesso à informação que, por sua vez, se configura como uma das etapas da gestão da informação.

O desenvolvimento deste estudo se justifica por buscar desmistificar a ideia de que a burocracia é um processo que atrapalha a eficiência das organizações. Pois, em tempos em que a informação, registrada ou não, é vista como recurso, torna-se importante compreender que a burocracia pode contribuir positivamente e fazer parte do processo da gestão da informação nos ambientes organizacionais.

\section{Max Weber e a Teoria da Burocracia}

Max Weber foi um sociólogo alemão pioneiro nos estudos voltados às organizações burocráticas. Foi ele quem idealizou a teoria da burocracia, vivenciada até hoje pela sociedade e pelas organizações presentes. Durante sua trajetória de vida, Weber estudou das mais variadas formas, os efeitos do capitalismo nos diversos setores da sociedade, envolvidos aos teores sociais, religiosos, econômicos e etc (TRAGTENBERG, 2006).

Segundo o autor, Max Weber foi também um dos precursores na pesquisa empírica, pois, realizou diversas pesquisas que buscavam analisar, por exemplo, a situação dos trabalhadores rurais alemães; a reação dos camponeses diante da migração rural-urbana; os efeitos pessoais e profissionais provocados nos operários a partir da introdução das máquinas; as variações quotidianas no ritmo de trabalho dos operários, mediante o grau de motivação desses, enfim, entre muitos outros tipos de pesquisas que, de certa forma, foram substanciais para que Weber se interessasse pelos gêneros burocráticos e políticos, que fato é, impactam nas organizações contemporâneas até nos dias de hoje.

Mediante Weber (1971), a teoria burocrática é a única forma de organizar de maneira efetiva um grande número de pessoas que realizam as mais diversas tarefas em um contexto organizacional. Segundo o autor, essa teoria confronta qualquer aspecto anarquista que não possui regras definidas e obrigatórias para a manutenção da ordem, além de promover o suprimento da era clássica e da teoria das relações humanas. A era clássica é uma ciência administrativa que foi desenvolvida por um engenheiro francês chamado Henri Fayol, essa teoria busca enfraquecer o senso comum e o aspecto empirista de uma organização por técnicas 
e métodos científicos (MAIA, 2010), enquanto que a teoria das relações humanas é uma corrente administrativa que enfatiza o ser humano na organização, suas necessidades e potencialidades dentro de um contexto de organização informal, opondo-se às teorias clássicas e foi criada por Elton Mayo (ROSSÉS et al., 2010).

A burocracia pode ser definida como uma teoria administrativa que visa formalizar as funções administrativas de uma empresa, tendo como base a impessoalidade, competência técnica e planos estabelecidos em longo prazo, pois trabalha em prol do desenvolvimento eficiente das atividades administrativas, diante de uma série de meios formais e registráveis (MENEGHETTI; FARIA, 2010; GROS, 2015).

Para os autores supracitados, os meios formais que a burocracia estabelece são compostos por diversas divisões de tarefas, habilitada pela estruturação hierárquica, que se configura uma das mais importantes funções da teoria da burocracia, e por isso está sempre atrelada ao poder, pois, acredita que a estruturação hierárquica contribui para a distribuição de tarefas e formalização das atividades desenvolvidas no âmbito diário.

De acordo com Motta e Vasconcelos (2008), a burocracia pode ser considerada um sistema que busca organizar de forma especializada o comportamento humano em um contexto organizacional, por meio do estabelecimento de regras e regulamentos formais que se direcionam para a efetividade das tarefas e das tomadas de decisões.

Segundo Chiavenato (2007) e Maximiano (2011), a burocracia é vista como uma máquina administrativa, que influência os funcionários de uma empresa a agirem estritamente com base nas regras, normas e regulamentos que são estabelecidos, e de modo algum por interesses pessoais.

No entanto, pode-se dizer que a construção hierárquica e a definição de regras altamente formas e sistemáticas que a teoria da burocracia traz consigo, pode facilmente induzir os funcionários a executarem atividades de forma mecânica, sem o mínimo de lógica, e ao mesmo tempo, atrapalhar seu desenvolvimento como ser pensante, que produz e acessa informação para tomadas de decisão eficazes, mesmo porque, as normas impostas pela burocracia nem sempre podem condizer à efetividade de determinada atividade prática.

Tragtenberg (2006) defende que o cumprimento da teoria burocrática resulta na precisão, rapidez e discrição dos processos organizacionais, assim como assegura a ausência de conflitos e custos excessivos, mediante uma rigorosa subordinação. Para o autor, a gestão 
autocrática pode ser a solução para todos os problemas de uma organização, entretanto, essa é uma lógica que deve ser contestada, porque, nesse contexto, não há como levar em consideração o sujeito organizacional como um ser pensante e valorizado no ambiente organizacional, mesmo porque, onde há excesso de autocracia, não há democracia, e é arriscado incentivar a ideia de que a burocracia pode ser aliada da autocracia e não da democracia nas organizações.

A teoria da burocracia, originalmente, surgiu na década de 1940, com o intuito maior de resolver as críticas existentes às teorias organizacionais na época existentes, como a clássica de Henry Fayol, que tinha como forte característica o excesso de atividades mecânicas, e a teoria das relações humanas de Elton Mayo, que por sua vez, era o oposto da primeira, e atribuía atenção e valoração exaustiva ao homem como funcionário, deixando de lado os processos administrativos (REIS et al., 2013).

Porém, Oliveira (2009) afirma ser em 1909 que a teoria da burocracia começou a se desenvolver, em uma busca restrita à análise das questões administrativas das organizações, e que seu surgimento é marcado pela década de 1940, pois Max Weber concluiu o livro intitulado 'A teoria da organização social e econômica', que já abordava o inicieinício da teoria em 1910, mas que fora publicado apenas 37 anos depois.

De forma geral, o quadro um apresenta as principais contribuições para a teoria da burocracia e seus idealizadores, desde a década de 1910, a fim de que se compreenda com mais afinco as características do processo burocrático nas organizações contemporâneas.

Quadro 1 - Idealizadores e Principais contribuições para a Teoria da Burocracia

\begin{tabular}{|c|c|c|}
\hline Idealizador & Ano & Principais contribuições \\
\hline Max Weber & 1910 & - Idealizador da Teoria da Burocracia. \\
\hline Philip Selznick & 1947 & $\begin{array}{l}\text { - Trabalhou a questão da delegação de } \\
\text { autoridade. } \\
\text { - Afirmou que a burocracia é adaptativa } \\
\text { e dinâmica, interagindo fortemente com } \\
\text { o ambiente externo. }\end{array}$ \\
\hline $\begin{array}{l}\text { Robert Merton (com } \\
\text { A.P. Gray, B. Hockey e } \\
\text { H. Selvin) }\end{array}$ & 1952 & $\begin{array}{l}\text { Introduziram aperfeiçoamentos para a } \\
\text { aplicação da teoria: } \\
\text { - estabelecimento de objetivos para as } \\
\text { normas, procedimentos e regras; } \\
\text { - tratamento das questões pessoais nos } \\
\text { relacionamentos nas organizações; } \\
\text { - influência do nível de conhecimento } \\
\text { como base para as boas decisões; e }\end{array}$ \\
\hline
\end{tabular}




\begin{tabular}{|c|c|c|}
\hline & & $\begin{array}{l}\text { - amenização da questão do elevado } \\
\text { formalismo das normas } \\
\text { procedimentos. }\end{array}$ \\
\hline Peter Blau & 1956 & $\begin{array}{l}\text { - A burocracia ocorre principalmente nas } \\
\text { grandes organizações, mas elas não são } \\
\text { estáticas, podendo ocorrer mudanças de } \\
\text { forma oficial ou de forma espontânea, } \\
\text { decorrentes de influências externas e } \\
\text { internas das organizações. }\end{array}$ \\
\hline Robert Michels & 1959 & $\begin{array}{l}\text { - Analisou a burocracia em termos de } \\
\text { dominação e poder, e não como uma } \\
\text { forma estrutural das organizações. } \\
\text { - Criou o conceito de oligarquia, } \\
\text { referente a grandes e complexas } \\
\text { organizações, em que líderes dominam } \\
\text { tudo em proveito próprio e são } \\
\text { insubstituíveis. }\end{array}$ \\
\hline Amitai Etzioni & 1960 & $\begin{array}{l}\text { - Estabeleceu } 3 \text { tipos de poder: } \\
\text { - coercitivo: baseado em punições; } \\
\text {-manipulativo: baseado em barganhas e } \\
\text { recompensas; e } \\
\text { - normativo: baseado em crenças e } \\
\text { valores acreditados por todos. }\end{array}$ \\
\hline
\end{tabular}

Fonte: Oliveira (2009, p. 52).

A análise do quadro um permite identificar pontos positivos e negativos da burocracia, que foram construídos até o momento, desde a influência do nível de conhecimento como base para as boas decisões e amenização da questão formalista das normas e procedimentos até ao conceito característico dos tipos de poderes: coercitivo, manipulador e normativo, bem como a ideia autocrática de dominação e insubstituição dos líderes no contexto organizacional.

De acordo com Oliveira (2009), a teoria da burocracia foi a responsável pela consolidação de algumas características presentes na estruturação das organizações, tais como: (i) a formalização dos procedimentos, por meio da descrição dos cargos, elaboração de regras, políticas e regulamentos, e etc; (ii) aperfeiçoamento das atividades que são realizadas nas organizações, atrelada a total padronização das atividades e (iii) centralização do poder, oriunda do processo da mediação hierárquica. Nesse sentido, por essas características, fica evidente que mesmo voltando-se contra alguns aspectos da era clássica, pode-se afirmar que a teoria burocrática possui algumas bases teóricas que são provenientes da clássica.

Weber (1974; 1982) e Grzybovskki, Migott e Silva (2001) abordam algumas características que são fundamentais para o entendimento da teoria burocrática e da burocracia moderna. As características expressam que: (i) absolutamente todas as funções são executadas 
com base em normas e regulamentos; (ii) as responsabilidades e atribuições de cada cargo são claramente definidas a todos da organização, e cada cargo possui regras específicas a serem cumpridas; (iii) para toda tarefa existem regras que definem como realizá-la com eficiência. Essas regras são geralmente escritas e registradas no intuito de não haver confusão ou subjetividade na realização das funções; (iv) toda a administração é formalizada por meio de documentos responsáveis por regular a conduta dos funcionários (v) os sujeitos organizacionais devem executar suas funções sem direcionar suas vontades, ou seja, a burocracia possui a impessoalidade e a imparcialidade como dois dos seus principais princípios; (vi) a valorização do funcionário é medida conforme seu desempenho e alcance dos objetivos estabelecidos 'a priori', portanto, a burocracia incita a competitividade entre os funcionários que idealizam posições hierárquicas mais elevadas; (vii) os funcionários são submetidos a normas de controle rigorosas, mas, ainda sim, possuem liberdade no quesito pessoal, pois, somente devem cumprir as objeções relativas às tarefas do seu cargo em questão.

Com relação à maioria das características supracitadas, criticamente, a burocracia passa a ser considerada um processo alienador e que provoca conformismo ao funcionário, que manipula as necessidades de produção e consumo das pessoas, que por sinal, desaprendem como viver em comunidade (MOTTA, 1981).

Mas, para Oliveira (2009), a visão de Motta (1981) se dá pela forma em exagero que os métodos administrativos formais são enfatizados pela burocracia, sem levar em consideração as habilidades, conhecimento e criatividade das pessoas. Mediante Oliveira (2009), a burocracia somente será vista positivamente aos olhos populares, caso se adeque ao ritmo acelerado de mudanças na tecnologia, em que a liberdade de acesso à informação e a criação e utilização do conhecimento são cruciais para o sucesso estrutural de qualquer organização.

Para a sociedade em geral, a burocracia assume um papel negativo, sendo vista como papelada em demasia e sem necessidade, normas muito rígidas, sem objetivos lógicos e que não são compatíveis ao sucesso e agilidade dos processos e serviços de uma organização, porque mesmo com a intenção de organizar a estrutura da empresa para o alcance efetivo dos objetivos, algumas das suas características epistemológicas apresentaram algumas falhas justificadas pelo excesso de formalismo e registro em papel e pelo forte poder autocrático, que impedia o desenvolvimento criativo dos demais funcionários (CHIAVENATO, 2011).

No entanto, como toda teoria administrativa, a teoria da burocracia não é diferente; surgiu com intuito de proporcionar maior consistência das atividades das organizações, 
elevando-as a grandes níveis de eficiência e produtividade (OLIVEIRA, 2009). Segundo Dias (2008), esta teoria veio para implantar padrões de trabalho e normas que direcionassem as tarefas para o alcance dos objetivos organizacionais, pois, antes do seu desenvolvimento não existiam normas e padrões a serem seguidos.

Nesse sentido, Weber (1982) criou a burocracia com o intuito de atribuir caráter legal e formal as normas e regulamentos de uma organização, tornar a comunicação um registro memorial, dividir o trabalho de maneira racional, impondo menos pessoalidade nas tarefas e mais profissionalização e gerenciar e organizar todos os processos administrativos a fim de que cada tarefa seja realizada com sucesso pelos funcionários.

Neste âmbito, ao contrário do que muitos pensam, se for gerenciada em prol de tornar o acesso à informação mais fácil e a gestão da informação mais eficiente, a burocracia pode ser potencialmente importante no cenário atual, onde a informação é vista como um recurso importante nas organizações, utilizada essencialmente para os processos decisórios.

\section{A importância do acesso a informação para tomada de decisão}

Informação é um conceito amplo, que está envolvido com o mundo e sua vivência não carrega nenhum tipo de distinção, porque se encaixa na formalidade e na informalidade, nos âmbitos pessoais e profissionais, nas mais diversas áreas do conhecimento, pois, por meio dela a sociedade se desenvolve, as pessoas se realizam, se movimentam e sobrevivem.

Informação em momento algum se esconde, muito pelo contrário, ela transcende, não aceita quietude, pois é inquietude e não aceita apenas sobreviver, porque anseia por viver. Porém, é importante saber que esse tipo de informação possui valor agregado, que deve ser preservado por aqueles que a querem por perto, que querem por intermédio dela, evoluir seja em qual âmbito for, logo, é por isso que tanto se divulga a informação como recurso valioso, como um elemento que possui preço, custo e valor, como conceituam Fadel e Moraes (2008). Então, em síntese, informação, mais do que tudo, é capital.

Segundo Araújo (2017), informação é um processo capaz de transformar dados em conhecimento, e que se relaciona com a cultura, memória, apropriação, mediação, documento e saberes, além de ter funções objetivas de transferir algo de um sujeito ao outro, com a imensa capacidade de transformar o estado cognitivo e mental desses sujeitos. Então, ao analisar o 
conceito de informação que o autor supracitado traz ao campo da Ciência da Informação, temse também que informação é poder, além de capital, ou que é um meio, uma ferramenta que gera poder e capital.

Entretanto, mais do que isso, a informação possui práticas sociais que estão associadas ao desenvolvimento humano, pois, é um elemento presente em todas as situações do cotidiano das pessoas, que por sua vez, a utilizam para qualquer ação básica ou até mesmo complexa, portanto, sua perspectiva parte do ato de transformar e de alterar condições (SAEGER et al., 2016).

De acordo com Calazans (2008), a informação presente nos ambientes organizacionais é considerada um recurso imprescindível para a realização das tarefas diárias, porque se configura um insumo que auxilia na formulação dos objetivos e no alcance desses, além de contribuir para o monitoramento e desempenho das organizações. O avanço da tecnologia e o aumento do nível da concorrência evidenciam ainda mais a importância da informação nos processos de inovação e tomada de decisão de uma empresa, visto que esse é um ativo que pode ser comparado ao capital, propriedade, recursos humanos e bens materiais, portanto, necessita ser gerenciado e levado em consideração com muita seriedade (MCGEE; PRUSAK, 1994; CALAZANS, 2008).

Capurro (2003) concorda com McGee e Prusak (1994), ao dizer que a informação é um elemento complexo, que exige altos níveis de competências e especialidades de quem a utiliza buscando efetividade e excelentes resultados. Ademais, a autora também cita o avanço das tecnologias de informação e comunicação como ferramentas que estão cada vez mais incentivando as pessoas a se especializarem e se conscientizarem do valor que possui a informação no contexto organizacional.

Segundo Calazans (2008), toda informação presente nas organizações pode possuir caráter estratégico e pode ser utilizada para tomada de decisão, se estiver sendo tratada e gerenciada por um foco estratégico, de agregação de valor aos produtos e serviços oferecidos. Mas, ao mesmo passo, agregar valor aos produtos e serviços por meio da informação requer o uso de dados e conhecimento, tendo em vista que com dados se constrói informação e com informação estratégica se constrói conhecimento estratégico para tomadas de decisões.

Ao passo que tomar decisão significa um processo que identifica e encontra uma forma de solucionar problemas, por intermédio da ação (DAFT, 2006), pode-se apontar o porquê da 
informação está sendo atrelada ao conceito de tomada de decisão: porque não há como, de fato, encontrar e solucionar um problema sem acesso e uso da informação.

[...] no estágio de identificação do problema, a informação sobre as condições ambientais e organizacionais é monitorada para determinar se o desempenho é satisfatório e para diagnosticar a causa das falhas. O estágio de solução do problema se dá quando os caminhos alternativos de ação são considerados e uma alternativa é selecionada e implementada (DAFT, 2006, p. 372).

De acordo com Sobral e Peci (2013, p.145), a tomada de decisão é a "escolha entre alternativas ou possibilidades com o objetivo de resolver um problema ou aproveitar uma oportunidade". Nesse caso, Lousada e Valentim (2011) enfatizam a importância da informação para tomada de decisão, afirmando que o ato de tomar decisões está estabelecido nas ações profissionais de qualquer pessoa, pois faz parte das funções tanto de gestores como de funcionários.

Ao mesmo passo, a tomada de decisão deve ser compreendida como uma etapa futura, que apenas alcança o seu sucesso se anteriormente contar com processos de gestão da informação e gestão dos fluxos informacionais que tornam válido o acesso à informação. Mais do que gerenciar e agregar valor a informação, uma organização deve saber trabalhar ações que favoreçam o acesso à informação.

De acordo com Saeger et al., (2018), o acesso a informação se relaciona com os processos de comunicação, seleção e interpretação da informação, além de solicitar gerenciamento voltado a questão física do suporte, como também de competências informacionais que atribuem validade ao acesso. Anteriormente, o acesso passa por um processo de identificação de necessidades informacionais, de seleção e validação, e que posteriormente dá liberdade ao uso. Então, evidencia-se que o uso da informação apenas é possível se o acesso for autorizado e disponibilizado aos funcionários de uma organização.

Por fim e de maneira geral, Saeger et al., (2018) acredita que a informação como recurso estratégico para tomada de decisão claramente necessita de gerenciamento e de atividades efetivas que busquem impedir práticas vagarosas que atrapalhem o tratamento e a atribuição de valor à informação organizacional, e que possam facilitar a disponibilização e o acesso dessa informação. 


\section{Burocracia e Gestão da Informação}

Segundo Cruz (2006), utilizar aspectos da burocracia é necessário para a empresa que busca solucionar os seus problemas com medidas globais e estabilizadas. Segundo o autor, burocracia é um conjunto de métodos teóricos que objetivam nortear a prática dos indivíduos organizacionais no alcance dos seus objetivos e nas diárias tomadas de decisões.

Dessa maneira, diante de métodos teóricos e funções burocráticas, como a seleção de pessoal, normas e regulamentos para cada atividade da empresa, distribuição de funções mediante a estrutura hierárquica, e etc, pode-se dizer que a burocracia é um dos elementos que são capazes de moldar aspectos da cultura organizacional de uma empresa, como sua maneira de ser e de agir.

A gestão da informação, juntamente com as medidas que dão praticidade ao acesso da informação por parte dos funcionários é dependente da forma como a cultura organizacional ou informacional é estruturada, logo, afirma-se que a forma como os aspectos burocráticos são executados pode prejudicar a eficiência da gestão da informação e permissão de um acesso efetivo de informação em um contexto organizacional, como também pode, ao contrário disso, potencializar essa gestão e esse acesso, de modo que a burocracia, nesse âmbito, possui duplo poder.

A gestão da informação é conceituada por Choo (2003) e Valentim (2004) como um conjunto de estratégias voltadas a identificação das necessidades informacionais, mapeamento dos fluxos formais, coleta, filtragem, análise, organização, armazenamento e disseminação de informações para o desenvolvimento das práticas de trabalho e tomada de decisão dos funcionários de uma organização.

Para Ponjuán Dante (2004, p.19, tradução nossa), a gestão da informação é "um processo mediante o qual se obtém, se desenvolve, ou se utilizam recursos básicos (econômicos, físicos, humanos, materiais) para o uso da informação dentro do ambiente organizacional e para a sociedade a qual serve [...]”. Passos de Oliveira (2010) corrobora com Ponjuán Dante (2004), e a acrescenta que o processo de gestão da informação é desenvolvido, de maneira específica aos três níveis da pirâmide organizacional: operacional, tático e estratégico, de forma que atenda as especificidades de cada nível.

Assim, com o intuito de demonstrar a relação entre a teoria da burocracia com a gestão da informação que dá efetividade ao acesso à informação nas organizações, o quadro dois 
apresenta algumas características negativas adotadas à organização burocrática e como essas podem interferir nas etapas principais de gestão da informação. O quadro 2 (dois) se baseou no modelo de gestão da informação de Valentim (2004) por ser um modelo detalhado sobre gestão da informação, além de ser transcrito em atividades (passo a passo) aplicáveis ao ambiente empresarial, no qual esse trabalho busca representar. A teoria burocrática é orientada e aplicada nos ambientes organizacionais e está direcionada aos conceitos de gestão administrativa, portanto, essa é a justificativa dada pelo uso do modelo de gestão da informação de Valentim (2004).

Quadro 2 - Implicações da Burocracia na Gestão da Informação

\begin{tabular}{|c|c|c|}
\hline $\begin{array}{c}\text { ASPECTOS } \\
\text { BUROCRÁTICOS }\end{array}$ & INFERÊNCIA & $\begin{array}{c}\text { PROCESSOS DE GESTÃ̃O } \\
\text { DA INFORMAÇÃO }\end{array}$ \\
\hline $\begin{array}{l}\text { Falta de autonomia do } \\
\text { funcionário. }\end{array}$ & $\begin{array}{l}\text { pode prejudicar o } \\
\text { processo de: }\end{array}$ & $\begin{array}{l}\text { Identificação das necessidades } \\
\text { de informação }\end{array}$ \\
\hline Reuniões sem propósitos. & $\begin{array}{l}\text { pode prejudicar o } \\
\text { processo de: }\end{array}$ & $\begin{array}{l}\text { Elaboração de produtos e } \\
\text { serviços informacionais }\end{array}$ \\
\hline $\begin{array}{l}\text { Desorganização de } \\
\text { documentos e do ambiente } \\
\text { de trabalho. }\end{array}$ & $\begin{array}{l}\text { pode prejudicar os } \\
\text { processos de: }\end{array}$ & $\begin{array}{l}\text { Mapeamento e } \\
\text { reconhecimento de fluxos } \\
\text { formais; Prospecção e } \\
\text { monitoramento de } \\
\text { informações; e Coleta, seleção } \\
\text { e filtragem de informações. }\end{array}$ \\
\hline $\begin{array}{l}\text { Falta de estipulação de } \\
\text { prazos para cada tarefa. }\end{array}$ & $\begin{array}{l}\text { pode prejudicar o } \\
\text { processo de: }\end{array}$ & $\begin{array}{l}\text { Fixação de normas e padrões } \\
\text { de sistematização da } \\
\text { informação. }\end{array}$ \\
\hline $\begin{array}{l}\text { Desatualização de normas e } \\
\text { regulamentos. }\end{array}$ & $\begin{array}{l}\text { pode prejudicar os } \\
\text { processos de: }\end{array}$ & $\begin{array}{l}\text { Mapeamento e } \\
\text { reconhecimento de fluxos } \\
\text { formais e Elaboração de } \\
\text { produtos e serviços } \\
\text { informacionais. }\end{array}$ \\
\hline $\begin{array}{l}\text { Falta de um organograma } \\
\text { bem exemplificado. }\end{array}$ & $\begin{array}{l}\text { pode prejudicar os } \\
\text { processos de: }\end{array}$ & $\begin{array}{l}\text { Identificação das necessidades } \\
\text { de informação; Elaboração de } \\
\text { produtos e serviços } \\
\text { informacionais e Fixação de } \\
\text { normas e padrões de } \\
\text { sistematização da informação. }\end{array}$ \\
\hline $\begin{array}{l}\text { Falta de incentivo a opinião } \\
\text { e criatividade dos } \\
\text { funcionários. }\end{array}$ & $\begin{array}{l}\text { pode prejudicar o } \\
\text { processo de: }\end{array}$ & $\begin{array}{l}\text { Desenvolvimento de uma } \\
\text { cultura organizacional positiva } \\
\text { em relação ao } \\
\text { compartilhamento/socialização } \\
\text { da informação. }\end{array}$ \\
\hline $\begin{array}{l}\text { Não adequação ao 'pós- } \\
\text { custodial', guarda e } \\
\text { digitalização de documentos. }\end{array}$ & $\begin{array}{l}\text { pode prejudicar os } \\
\text { processos de: }\end{array}$ & $\begin{array}{l}\text { Mapeamento e } \\
\text { reconhecimento dos fluxos } \\
\text { formais; Prospecção e }\end{array}$ \\
\hline
\end{tabular}




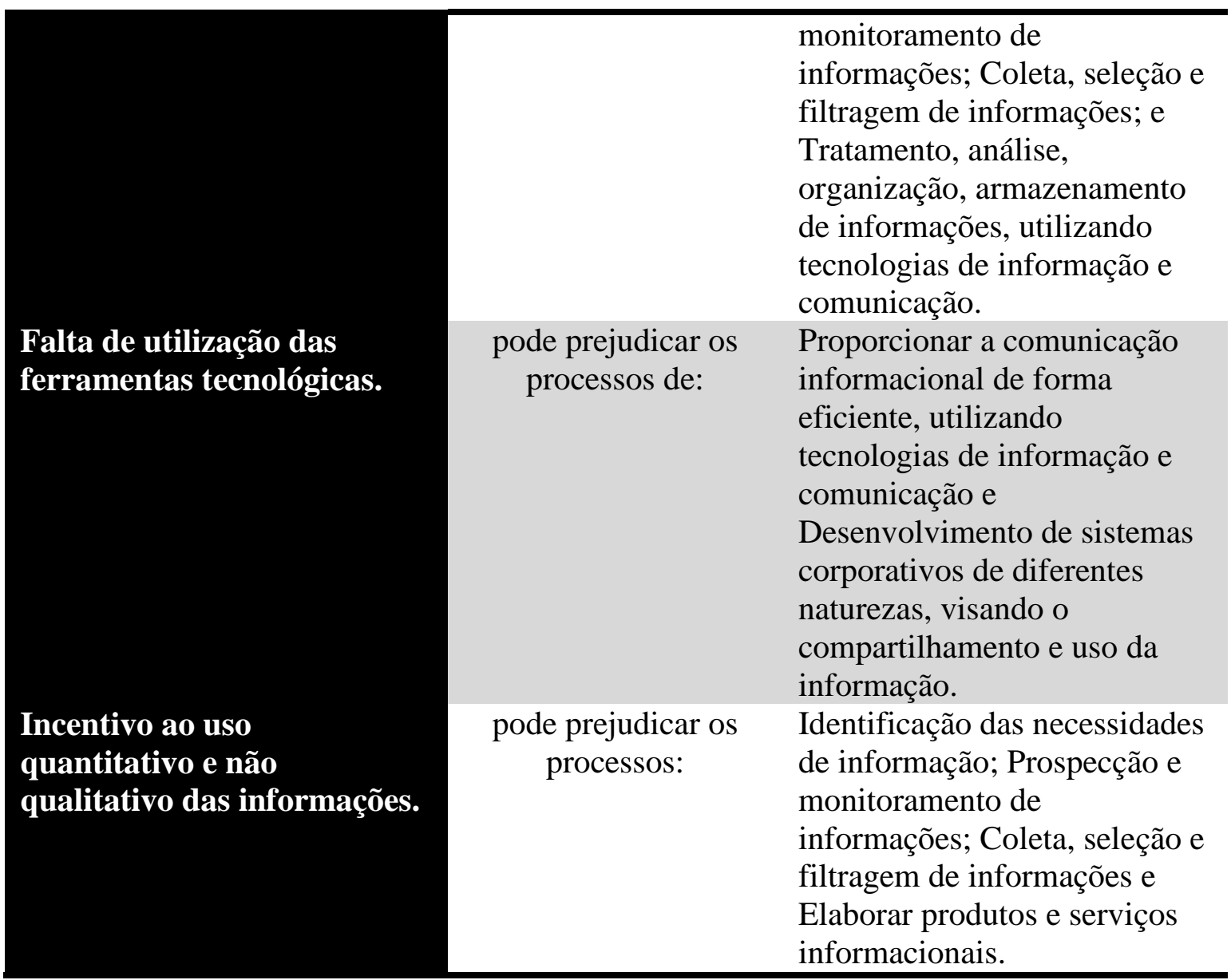

Fonte: Elaborado pelas autoras com base em Valentim (2004).

Mediante reflexões resultantes do referencial teórico da pesquisa e da experiência profissional com ambientes organizacionais, tanto públicos como privados, o quadro dois foi desenvolvido e organizado com o intuito de demonstrar como alguns aspectos negativos referentes à burocracia podem prejudicar os processos de gestão da informação sem ambientes organizacionais.

Quando o funcionário não possui autonomia, dificilmente será capaz de identificar suas reais necessidades de informação diante de alguma tarefa não corriqueira que possa ocorrer, porque a falta de autonomia pode engessar as habilidades de um indivíduo, tornando-o totalmente dependente de outras pessoas ou de normas já estabelecidas, que muitas vezes não condizem com suas necessidades em determinada situação.

Por isso, a atualização de normas e regulamentos de uma empresa torna-se imprescindível, afinal, muitas das normas estabelecidas podem não mais condizerem com a realidade de uma empresa e dos seus funcionários, o que pode ser prejudicial ao processo de mapeamento de fluxos formais de informação e de elaboração de produtos e serviços de informação, pois, se os funcionários não reportarem a normas e regulamentos atuais, 
dificilmente irão obter sucesso no mapeamento de informação realmente valiosa, que são essenciais na elaboração de produtos e serviços informacionais.

Outros aspectos que podem prejudicar o processo de mapeamento é a desorganização de documentos e do ambiente de trabalho e a falta de digitalização de documentos, mesmo porque não se pode mapear informação de maneira eficiente, sem que esta esteja organizada, principalmente na era pós-custodial vivenciada atualmente, em que os documentos são organizados no ambiente digital. E mais do que prejudicar o processo de mapeamento, esses aspectos dificultam o desenvolvimento das atividades relativas ao tratamento de informações.

De acordo com Motta (1981), uma das características mais negativas que a burocracia pode acarretar é a rigidez e alienação que provoca aos funcionários, que por seguirem restritamente as implicações hierárquicas da empresa, passam a naturalmente perder suas capacidades de utilização do próprio conhecimento na realização de suas atividades. Por isso, a falta de incentivo à expressão de opinião e a criatividade dos funcionários, pode prejudicar o processo de desenvolvimento de uma cultura organizacional positiva em relação ao compartilhamento da informação, pois, esses se fecham e determinam a si mesmos seguirem regras que lhes são estipuladas sem o mínimo de contestação, por assim não enxergam a necessidade de se comunicarem ou de se consultarem com outros funcionários.

Pode-se dizer que um momento interessante para se incentivar a criatividade, a expressão opinativa e o uso do conhecimento é o momento que acontecem as reuniões grupais, que devem acontecer sempre com algum propósito, uma pauta e objetivos a serem alcançados, afinal, reuniões que são feitas apenas para cumprir tarefas estéticas se configuram em perda de tempo, dinheiro e eficácia, além de sucessivamente dificultar a elaboração efetiva de produtos e serviços informacionais aos funcionários, clientes e stakeholders em geral.

A construção de níveis hierárquicos não deve ser considerada prejudicial, mas sim o aproveitamento de um poder exacerbado e rígido que alguns cargos carregam em virtude do ego. Logo, um organograma que especifique normas, regulamentos e atividades que devem ser seguidos por cada cargo ou setor é essencial para o processo de identificação das necessidades de informação, elaboração de produtos e serviços informacionais e principalmente para a fixação de normas e padrões de sistematização da informação, pois, o organograma é capaz de nortear, como ponto de referência, as atividades e tomadas de decisão de cada indivíduo da organização. Além disso, a estipulação de prazos para cada atividade também se torna essencial para o sucesso da gestão e eficiência organizacional, pois assim, os funcionários conseguem 
definir métodos individuais para trabalhar melhor com o tempo, desde que cumpram com o que foi estabelecido.

Por fim, infere-se que a utilização de ferramentas tecnológicas otimiza a comunicação informacional visando a solidificação da cultura do compartilhamento de informações, além de minimizar os serviços que geram papelada em demasia ou metodologias ultrapassadas, que não agregam valor as tarefas e aos seus reais propósitos. Nesse sentido, presume-se que os gestores necessitam incentivar o acesso e o uso qualitativo e não quantitativo de informações, porque, de acordo com Saeger et al., (2016), o excesso de canais para acesso à informação e o excesso da própria informação podem se transformar em obstáculos que danificam a utilização eficaz da informação nos processos organizacionais.

\section{Considerações finais}

Essa pesquisa buscou responder ao seguinte problema: no contexto organizacional, qual é o papel da burocracia nos processos de gestão da informação? Mediante esse problema, o objetivo foi analisar as implicações positivas e negativas da burocracia e demonstrar como potencializar suas implicações positivas nos ambientes organizacionais, a fim de facilitar o processo de gestão da informação.

De forma popular, a burocracia não é vista como uma teoria administrativa que objetiva tornar eficiente as tarefas práticas de uma organização, através do uso de normas e regulamentos estabelecidos na estrutura da empresa. De fato, essa visão não surgiu sem motivos, pois, de modo geral, a forma como as empresas utilizam os vieses burocráticos configura-se deturpada e desatualizada, porque são seguidas e aplicadas sem criatividade e raciocínio.

Principalmente no contexto atual em que as organizações encontram-se inseridas, onde o gerenciamento para o acesso e o uso da informação são importantes e requisitados, é importante começar a refletir sobre fatores que possam atrapalhar a otimização da informação no ambiente organizacional, e concomitantemente, começar a analisar formas de auxiliar o processo de gestão da informação, pois é este o responsável por preservar a informação, considerado ativo e recurso de valor, essencial para o desenvolvimento e aumento do nível de competitividade das empresas. 
Por isso, escolheu-se nessa pesquisa abordar a burocracia, como possível processo que pode auxiliar a gestão da informação, como também prejudicar, dependendo da forma como é aplicada. Nesse caso, indica-se que os gestores e empresários observem os aspectos burocráticos do quadro dois e corrijam esses problemas visando à melhoria na sua gestão da informação. Ademais, conclui-se que a gestão da informação não consegue ser implantada, na prática, com eficiência se na organização existir uma burocracia com características ultrapassadas e não combinadas com a sociedade da informação. Então, como resposta ao problema de pesquisa, o papel da burocracia pós-moderna na gestão da informação é trabalhar em prol da autonomia do funcionário, da organização e da gestão documental, da atualização de normas e regulamentos, do incentivo a socialização e compartilhamento da informação e do conhecimento entre os funcionários e especialmente incentivar a criatividade e o ato de pensar do funcionário, como também ao uso e acesso qualitativo da informação.

Por fim, como apoio ao desenvolvimento de pesquisas futuras, indica-se investigações que visem analisar as implicações dos aspectos burocráticos na gestão da informação de uma empresa, por meio de uma pesquisa de campo; como também se indica o desenvolvimento de um trabalho que coloque em prática os aspectos positivos da burocracia, a fim de validar as implicações com a gestão da informação, desenvolvidas nessa pesquisa.

\section{Agradecimentos}

À Coordenação de Aperfeiçoamento de Pessoal de Nível Superior (CAPES) e ao Conselho Nacional de Desenvolvimento Científico e Tecnológico (CNPq) pelo financiamento desta pesquisa. 


\section{Referências}

ARAÚJO, C. A. Á. Teorias e tendências contemporâneas da Ciência da Informação. Informação em Pauta, Fortaleza, v. 2, n. 2, p. 9-34, 2017. Disponível em: http://www.periodicos.ufc.br/informacaoempauta/article/view/20162. Acesso em: 02 mar. 2018.

ARDENGHI, R. S. Direito à vida privada e direito à informação: colisão de direitos fundamentais. Revista da ESMESC, Florianópolis, v. 19, n. 25, 2012. Disponível em: https://revista.esmesc.org.br/re/article/view/57. Acesso em: 02 mar. 2018.

CALAZANS, A. T. S. Qualidade da informação: conceito e aplicações. Transinformação, Campinas, v. 20, n. 1, p. 29-45, 2008. Disponível em:

http://www.scielo.br/scielo.php?pid=S010337862008000100003\&script=sci_abstract\&tlng=pt. Acesso em: 03 mar. 2018.

CAPURRO, R. Epistemologia e Ciência da Informação. In: ENCONTRO NACIONAL DE PESQUISA EM CIÊNCIA DA INFORMAÇÃO, 5., 2003. Anais... Belo Horizonte: ANCIB, 2003.

CHIAVENATO, I. Introdução à teoria geral da administração. 7. ed. Rio de Janeiro: Elsevier, 2003.

CHIAVENATO, I. Administração dos recursos humanos. 6. ed. São Paulo: Atlas, 2007.

CHIAVENATO, I. Introdução à teoria geral da Administração: uma nova visão

abrangente da moderna administração das organizações. 8. ed. Rio de Janeiro: Elsevier, 2011.

CHOO, C. W. A organização do conhecimento: como as organizações usam a informação para criar significado. São Paulo: Senac Editora, 2003.

CRUZ, J. A. W. A burocracia fora do senso comum. Perspectivas Contemporâneas, Campo Mourão, v. 1, n, 1, 2006. Disponível em:

http://revista.grupointegrado.br/revista/index.php/perspectivascontemporaneas/article/view/36 1. Acesso em: 04 mar. 2018.

DAFT, R. Organizações: teoria e projetos. São Paulo: Thomson, 2006.

DIAS, R. Sociologia das organizações. São Paulo: Atlas, 2008.

FADEL, B.; MORAES, C. R. B. A informação no contexto organizacional: tipos, características e usos. Revista de sistemas de información y documentación, Zaragoza, v. 1, p. 33-41, 2008. Disponível em: http://ibersid.eu/ojs/index.php/ibersid/article/view/2199/1960. Acesso em: 05 mar. 2018.

GONÇALEZ, R. R.V.A. Repositórios arquivísticos digitais confiáveis: identificação de requisitos com ênfase no acesso a informação (Tese de doutorado). Faculdade de Filosofia e Ciências, Universidade Estadual Paulista, Marília, 2017. 
GROS, A. E. Burocratización y racionalización en Max Weber a la luz de las interpretaciones actuales de su obra. Questión, Buenos Aires, v. 45, n. 1, p. 115-127, 2015. Disponível em: http://perio.unlp.edu.ar/ojs/index.php/question/article/view/2388. Acesso em: 01 mar. 2018.

GRZYBOVSKI, D.; MIGOTT, A.; SILVA, L. A. A. A aplicação conceitual da teoria da burocracia na área da enfermagem: uma análise empírica das instituições hospitalares de Passo Fundo (RS). São Paulo: Caderno de Pesquisas em Administração, 2001.

LOUSADA, M.; VALENTIM, M. L. P. Modelos de tomada de decisão e sua relação com a informação orgânica. Perspectivas em Ciência da Informação, Belo Horizonte, v. 16, n. 1, p. 147-164, 2011. Disponível em:

http://portaldeperiodicos.eci.ufmg.br/index.php/pci/article/view/1028. Acesso em: 04 mar. 2018.

MAIA, V. I. Administração científica e clássica: a visão dos homens que construíram a base da gestão organizacional moderna. Revista Digital FAPAM, Pará de Minas, v. 2, n. 2, p. 8589, 2010. Disponível em: https://periodicos.fapam.edu.br/index.php/synthesis/article/view/36. Acesso em: 04 mar. 2018.

MAXIMIANO, A. C. Introdução à administração. 8. ed. São Paulo: Atlas, 2011.

MCGEE, J; PRUSAK, L. Gerenciamento estratégico da informação: aumente a competitividade e a eficiência de sua empresa utilizando a informação como uma ferramenta estratégica. Rio de Janeiro: Campus, 1994.

MENEGHETTI, F. K.; FARIA, J. H. Burocracia como organização, poder e controle: anais do Encontro da ANPAD, Rio de Janeiro: 34, 2010.

MOTTA, F. C. P. O que é burocracia. São Paulo: Brasiliense, 1981.

MOTTA, F. C. P.; VASCONCELOS, I. F. G. T. Teoria geral da administração. 3. ed. São Paulo: Cengage Learning, 2008.

OLIVEIRA, D. P. R. Teoria geral da administração: edição compacta. São Paulo: Atlas, 2009.

PONJUÁN DANTE, G. Gestión de información: dimensiones e implementación para el éxito organizacional. Rosario: Nuevo Parhadigma, 2004.

REIS, A. L.; DAVID, G. C.; CHAGAS, H. S.; MENDONÇA, M. P. A cultura organizacional e a burocracia: a influência de um ambiente burocrático dentro de uma organização. Fórum de Administração, v. 5, n. 1, p. 1-15, 2013. Disponível em:

http://periodicos.unifacef.com.br/index.php/forumadm/article/view/770/70. Acesso em: 01 mar. 2018.

ROSSÉS, G. F.; GELATTI, C. B.; SILVA, A.; PASSOS, L. J.; AMARAL, L. S. Teoria das relações humanas e economia solidária: o caso do projeto Esperança/Cooesperança. In: SIMPÓSIO DE EXCELÊNCIA DE GESTÃO E TECNOLOGIA, 7., 2010. Anais... Rio de Janeiro, 2010. 
SAEGER, M. M. M.T.; OLIVEIRA, M. L. P.; PINHO NETO, J. A. S.; NEVES, D. A. B. Organização, acesso e uso da informação: componentes essenciais ao processo de gestão da informação nas organizações. Páginas a\&b, Porto, v. 3, n. 6, 2016. Disponível em: http://ojs.letras.up.pt/index.php/paginasaeb/article/view/1545. Acesso em: 02 mar. 2018.

SOBRAL, F.; PECI, A. Administração: teoria e prática no contexto brasileiro. 2. ed. São Paulo: Pearson Prentice Hall, 2013.

TRAGTENBERG, M. Burocracia e ideologia. 2. ed. São Paulo: Ed. UNESP, 2006.

WEBER, M. Ensaios de sociologia. Rio de Janeiro: Zahar, 1971.

WEBER, M. Economia y sociedad: esbozo de sociologia compreensiva. 2. ed. Ciudad del Mexico: Fondo de Cultura Económica, 1974.

WEBER, M. Ensaios de sociologia. 5. ed. Rio de Janeiro: LTC, 1982.

VALENTIM, M. L. P. Gestão da informação e gestão do conhecimento: especificidades e convergências. 2004. Disponível em:

http://www.ofaj.com.com/colunas_conteudo.php?cod=88. Acesso em: 05 mar. 2018.

Artigo submetido em: 30 ago. 2018

Artigo aceito em: 01 abr. 2020 